\title{
Energy expenditure after spinal cord injury in people with motor- complete tetraplegia or motor-complete paraplegia
}

\author{
Tobias Holmlund $^{1,2} \cdot$ Elin Ekblom-Bak ${ }^{3}$ Erika Franzén ${ }^{4,5} \cdot$ Claes Hultling $^{1} \cdot$ Kerstin Wahman $^{1,2}$
}

Received: 30 May 2017 / Revised: 29 September 2017 / Accepted: 4 October 2017 / Published online: 14 December 2017

(c) International Spinal Cord Society 2018

\begin{abstract}
Study design Cross-sectional.

Objectives This study aimed to describe and compare $\mathrm{VO}_{2}$ and energy expenditure at rest (REE) and during standardized sedentary, non-exercise physical activity, and exercise activities, in people with motor-complete tetraplegia (C5-C8). Further, REE and energy expenditure (EE) for the different activities were compared to data from a reference group of people with motor-complete paraplegia (T7-T12).

Setting Sweden.

Methods The sample of people with motor-complete tetraplegia consisted of 26 adults (seven women) with SCI, C5-C8 AIS A-B. REE and EE for the different activities were measured with indirect calorimetry. The results were further compared to people with motor-complete paraplegia.

Results Resting $\mathrm{VO}_{2}$ was $2.57 \mathrm{ml} \mathrm{O}_{2} \mathrm{~kg}^{-1} \mathrm{~min}^{-1}, 2.54$ for men and 2.60 for women. The $\mathrm{VO}_{2}$ or activity energy expenditure related to body weight increased three to four times during non-exercise physical activity compared to sedentary activities for the people with motor-complete tetraplegia, and up to six times during exercise activity. No significant differences were seen in resting or sedentary activity $\mathrm{VO}_{2}$ between the people with motor-complete tetraplegia and those with motor-complete paraplegia. Activities of daily life revealed no or small differences in $\mathrm{VO}_{2}$, except for setting a table, while the people with tetraplegia had $\sim 50 \%$ lower $\mathrm{VO}_{2}$ during exercise activities.

Conclusions Non-exercise physical activities of daily life may be significant for increasing total daily EE in people with motor-complete tetraplegia. This might act to motivate the individual, and might be clinically important when designing adapted lifestyle intervention programs for the target group.
\end{abstract}

Tobias Holmlund

tobias.holmlund@ki.se

1 Department of Neurobiology, Care Sciences and Society, Division of Neurodegeneration, Neurorehabilitation Section, Karolinska Institutet, SE-171 77 Solna, Sweden

2 Rehab Station Stockholm/Spinalis R\&D Unit, Frösundaviks allé 4, SE-169 89 Solna, Sweden

3 Åstrand Laboratory of Work Physiology, The Swedish School of Sport and Health Sciences, Lidingövägen 1, 11433 Stockholm, Sweden

4 Department of Neurobiology, Care Sciences and Society, Division of Physiotherapy, Karolinska Institutet, SE-171 77 Solna, Sweden

5 Function Area Occupational Therapy \& Physiotherapy, Allied Health Professionals Function, Karolinska University Hospital, SE-171 76 Stockholm, Sweden

\section{Introduction}

Spinal cord injury (SCI) is associated with a higher prevalence of overweight and a lower level of physical activity than that in the general population $[1,2]$. This may contribute to the high level of lifestyle-related diseases in the SCI population [3]. However, therapeutic lifestyle interventions and prevention programs targeting weight management and physical inactivity for the general population are not valid for the SCI population $[4,5]$. For some years there have been physical activity guidelines for adults with SCI [6]. Still, accurate data on energy expenditure (EE), and especially activity energy expenditure (AEE), are important for supplementing these guidelines and for developing evidence-based therapeutic lifestyle intervention programs for people with SCI.

Resting energy expenditure (REE) and AEE are lower in people with SCI than in the general population and 
much variation in REE is reported in previous studies with heterogeneous study populations and few participants [7-14]. A recent review article by Nevin et al. found contradictory results as to whether REE differs between different subgroups of the SCI population, such as those with tetraplegia and those with paraplegia, and men and women, when oxygen consumption is related to body weight [15].

Moreover, data on AEE for persons with SCI are limited, especially for motor-complete tetraplegia. One previous study reported that EE was lower during training sessions for wheelchair rugby players (tetraplegia) than during sessions for basketball players (paraplegia) and tennis players (paraplegia) [9]. Also, a study by Collins et al. reported that a person with tetraplegia takes 15 min longer to consume $150 \mathrm{kcal}$ than one with paraplegia during the same kind of exercise [10]. The difference in EE between tetraplegia and paraplegia could be explained by the fact that motorcomplete injuries above thoracic level 6 affect additional muscle tissue and control of the autonomic nervous system (ANS) $[9,10,16,17]$. The reduced interaction between the parasympathetic and sympathetic nervous systems leads to lower maximal heart rate $(100-130 \mathrm{bpm})$ and impaired respiratory function, with lower vital capacity [18]. This especially affects exercise performance, and leads to energy supply via anaerobic processes and higher levels of lactate at lower intensity levels than those in non-SCI subjects [18, 19]. Moreover, ANS cannot regulate blood pressure and this result in insufficient blood redistribution to the active muscles during exercise.

In a previous publication, we reported REE and AEE during 15 different standardized physical activities for people with motor-complete paraplegia T7-T12 [14]. In the present study, we aim to describe and compare resting $\mathrm{VO}_{2}$ and $\mathrm{EE}$, and $\mathrm{VO}_{2}$ and $\mathrm{EE}$, for different standardized sedentary, non-exercise, and exercise activities in people with motor-complete tetraplegia (C5-C8). Further, we aim to compare REE, TEE, and AEE during sedentary, nonexercise, and exercise activities between people with motorcomplete tetraplegia and a reference group of people with motor-complete paraplegia.

\section{Methods}

The study sample consisted of 26 persons (seven women) with motor-complete SCI, C5-C8 (tetraplegia sample) and a reference group of 38 persons (10 women) with motor-complete SCI, level T7-T12, paraplegia. The REE and AEE of this reference group have been reported previously [14].

All the participants were recruited through advertisements on SCI-specific websites or by word-of-mouth. After the initial contact, the participants were e-mailed with indepth information about the study and later contacted by telephone. Interested people were sent a consent form by email. Inclusion criteria were SCI injury level $\mathrm{C} 5-\mathrm{C} 8$ and for the reference group T7-T12; AIS A and B motor-complete, $\geq 1$ year post-injury, age $\geq 18$ years, with no or minimal spasticity, as reported on the spasm frequency scale (Penn) [20]. Exclusion criteria were known coronary artery disease, angina pectoris, chronic congestive heart failure, chronic obstructive pulmonary disease, hormone replacement therapy, or shoulder pain.

The REE data were collected in a laboratory environment and the activity data in a clinical setting. All participants participated in both the REE and the activities. The study was approved by the Stockholm regional ethics committee, reference number 2011/1989-31/1. All the participants gave their informed written consent to participate.

\section{Assessment of oxygen consumption at rest}

Oxygen consumption at rest and calculated REE were measured in a thermoneutral environment $\left(19-20^{\circ} \mathrm{C}\right)$ with indirect calorimetry (Jaeger Oxycon Pro, Hoechberg, Germany). The participants arrived in the morning between $06.30 \mathrm{a} . \mathrm{m}$. and $10.00 \mathrm{a} . \mathrm{m}$. after overnight fasting ( $>8 \mathrm{~h})$ and abstention from nicotine and caffeine. They were also asked to avoid heavy exercise $24 \mathrm{~h}$ before the testing, and to empty the bladder before testing. During the REE assessment the instruction was to lie supine and rest without talking or falling asleep. All tests were performed by the same investigator. Before each data collection the system was calibrated with high-precision gas from a tank, using built-in automated procedures. The measurements were recorded and analyzed with JLAB software (Carefusion, Hoechberg, Germany) and steady-state $\mathrm{VO}_{2^{-}}$ data $\left(\mathrm{L} \mathrm{min}^{-1}\right)$ were used to calculate EE (kcals) during resting.

\section{Assessment of oxygen consumption for the activities}

The standardized activities are given below in the order we followed. They were selected to represent a wide range of intensities; two sedentary activities, three non-exercise physical activities (NEPA) and seven exercise activities. These activities were selected as they are usually implemented during the active rehabilitation phase. The sedentary activities included television watching and desk-based computer work; the NEPA included setting a table following a standardized procedure, wheeling a manual wheelchair indoors at preferred walking pace or perceived as 10-11 (light exertion) on the Borg RPE scale, and wheeling 
Table 1 Characteristics of study participants

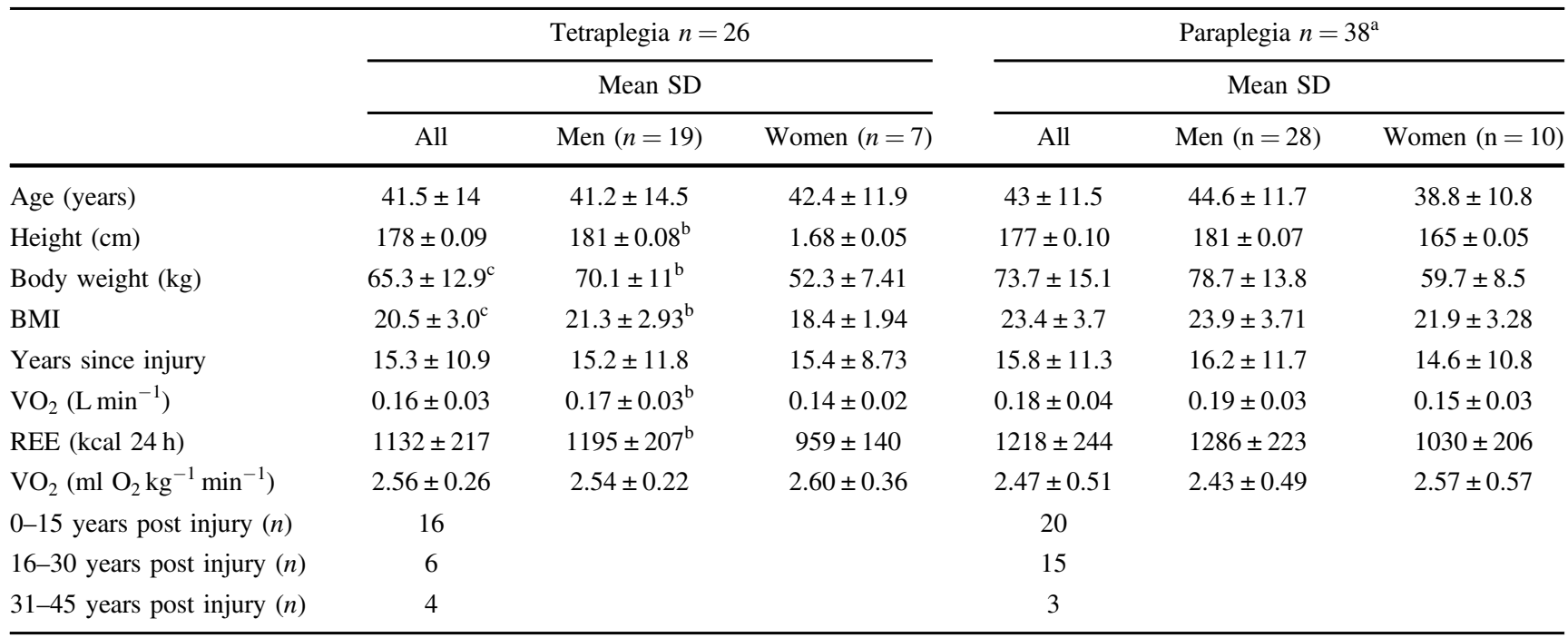

$B M I$ body mass index, REE resting energy expenditure

${ }^{a}$ Mean values published in Spinal Cord 2017

${ }^{\mathrm{b}}$ Significant difference between men and women tetraplegia

${ }^{\mathrm{c}}$ Significant difference between tetraplegia and paraplegia $p<0.05$

the wheelchair outside, Borg 10-11 [21, 22]. The exercise activities included wheelchair outside on asphalt at Borg 13-14, hand bike outdoors at 'exercise pace', Borg RPE 13-14 (somewhat hard), arm ergometer work at low level $(10-15 \mathrm{~W})$ or high level $(15-25 \mathrm{~W})$ at 60 r.p.m. (Ergomedic 891E Monark, Sweden), ski-ergometer, Borg 13-14, weight training implemented as $2 \times 10$ repetitions at each station (rowing machine, lats pulldowns and externa/internal rotation with cable), and circuit-resistance training modified from Nash et al. [23]. Speed of movement $\left(\mathrm{km} \mathrm{h}^{-1}\right)$ was measured for all wheeling-wheelchair activities, which made it possible to adjust EE for speed of movement. The activity testing was assessed with the Jaeger Oxycon Mobile system (Hoechberg, Germany), which was calibrated before each test with reference gases and room air. In addition it was calculated using the thermal equivalents of oxygen for the non-protein respiratory exchange ratio $\left(\mathrm{VCO}_{2} / \mathrm{VO}_{2}\right)$. Each test lasted for $6-7 \mathrm{~min}$ and the time between each activity varied between a few minutes (sedentary) and $>30 \mathrm{~min}$ (exercise activities). $\mathrm{VO}_{2}$ and $\mathrm{VCO}_{2}$ breath-by-breath and mean $\mathrm{VO}_{2}$ were measured during the activity. The values of the last 3 min were used to calculate the EE.

The same information regarding smoking and vigorous exercise was given in the prefatory e-mail with in-depth information. For the tests, information about each activity was given as a standardized verbal instruction together with pace (Borg) and how to select weight (gym). Body weight was measured to the nearest $0.1 \mathrm{~kg}$, and height was selfreported.

\section{Data analysis}

The indirect calorimetry measurements were recorded and analyzed using the JLAB software (Carefusion, Hoechberg, Germany). The thermal equivalents of oxygen for the nonprotein respiratory exchange ratio $\left(\mathrm{VCO}_{2} / \mathrm{VO}_{2}\right)$ were used for the $\mathrm{VO}_{2}$ data steady-state $\left(\mathrm{L} \mathrm{min}^{-1}\right)$ to calculate $\mathrm{EE}$ in kcals during rest and standardized activities. The lowest steady $\mathrm{VO}_{2}$ recorded for at least 10 min was used to calculate REE. MET values were assessed from individual resting $\mathrm{VO}_{2}\left(\mathrm{ml} \mathrm{O}_{2} \mathrm{~min}^{-1} \mathrm{~kg}^{-1}\right)$. AEE was calculated for each activity by subtracting the participant's individual REE from the total energy expenditure (TEE), to reduce intraindividual variation for REE and to enable comparison with the previous article, which included people with motorcomplete paraplegia.

\section{Statistical analysis}

For the sample of people with motor-complete tetraplegia, 19 of 288 activity values were skewed (assessed visually, skewness \pm 1.96 and, Kolmogorov-Smirnov) and presented as median (interquartile range, Q1-Q3), and the Mann-Whitney $U$ t-test was used to compare motorcomplete paraplegia and tetraplegia values. Normally distributed activity data are reported as mean (SD), and an independent $t$-test was used to compare between tetraplegia and paraplegia, as well as gender. Only descriptive statistics (mean SD or median and inter-quartile range) were applied 


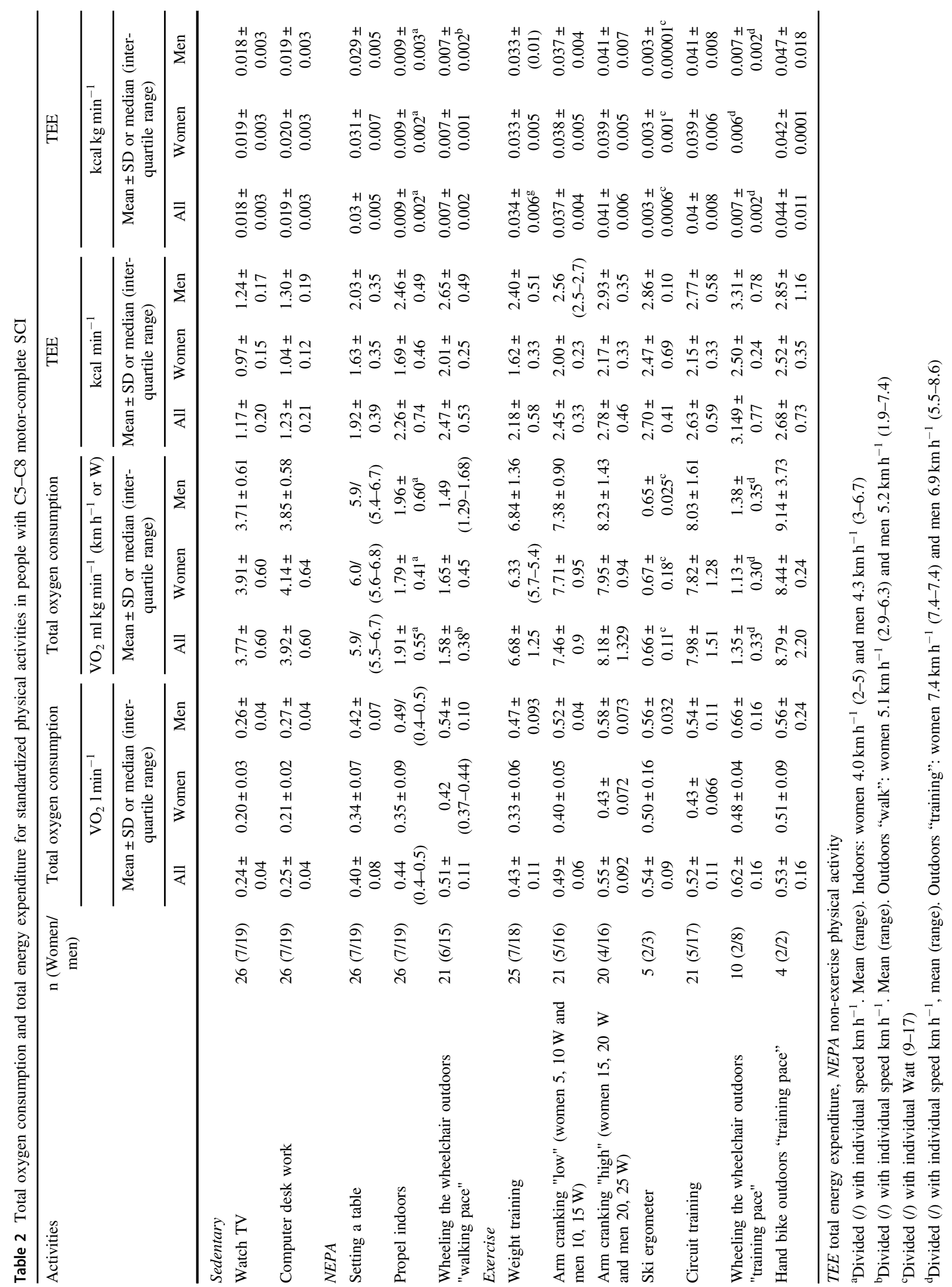


to activities with fewer than ten participants. Statistical analyses were performed using SPSS version 22.0.

\section{Results}

\section{Motor-complete tetraplegia}

Mean and SD values for resting $\mathrm{VO}_{2}$ for the sample of people with motor-complete tetraplegia were $0.16(0.03)$ $\mathrm{L} \mathrm{O}_{2} \min ^{-1}$ and, when adjusted for body weight, 2.56 (0.26) $\mathrm{ml} \mathrm{O}_{2} \mathrm{~min}^{-1} \mathrm{~kg}^{-1}$. Mean REE was 1132 (217) kcal per $24 \mathrm{~h}$ (Table 1). The men were in general taller, weighed more, and had significantly higher mean resting absolute $\mathrm{VO}_{2}$ and REE than the women had. However, these differences were attenuated after adjusting for body weight.

Total $\mathrm{VO}_{2}$ and TEE (Table 2) and activity $\mathrm{VO}_{2}$ and AEE (Table 3) are presented for all motor-complete tetraplegia and for women and men separately. The lowest mean total $\mathrm{VO}_{2}$ and TEE were found during sedentary activities, with a two-fold increase when wheeling wheelchair outdoors at walking pace (Borg 10-11) NEPA. Further, the highest mean total oxygen consumption and TEE values were obtained during exercise activities, and increased up to 2.6 times during wheelchair-wheeling outdoors at 'exercise pace' (Borg 13-14) compared to sedentary activities. Similarly, activity $\mathrm{VO}_{2}$ and AEE were lowest during sedentary activities, increasing 4 times when wheeling the wheelchair outdoors, Borg 10-11 (NEPA) and up to 6 times in exercise activities such as wheeling the wheelchair outdoors "exercise pace" (Table 3).

\section{Tetraplegia vs. the reference group with paraplegia}

Comparison of the characteristics of the participants with motor-complete tetraplegia and of those in the reference group with motor-complete paraplegia showed that the latter were $13 \%$ heavier $(p=0.02)$, and had a significantly higher BMI $(p=0.002)$ (Table 1).

Regarding EE at rest, the people with tetraplegia had a mean resting $\mathrm{VO}_{2}\left(0.16\right.$ vs. $0.18 \mathrm{~L} \mathrm{~min}^{-1}$ for those with paraplegia). The corresponding REE values were 1132 (216) vs. 1218 (244) kcal for those with paraplegia. This was slightly but not statistically significantly lower $(p=0.15)$. Adjusting for body weight further attenuated the difference between the groups, with even somewhat higher resting $\mathrm{VO}_{2}$ for the people with tetraplegia $(2.56(0.26)$ vs. 2.47 (0.51) $\mathrm{ml} \mathrm{O}_{2} \min ^{-1} \mathrm{~kg}^{-1}$ ).

Some of the comparable activities between the two subgroups for activity $\mathrm{VO}_{2}\left(\mathrm{ml} \mathrm{O}_{2} \mathrm{~min}^{-1} \mathrm{~kg}^{-1}\right)$ are presented in Fig. 1. There were no significant differences for sedentary activities, represented by desk work $(p=0.3)$, or in NEPA, such as standardized wheelchair wheeling indoors at $4.3 \mathrm{~km} \mathrm{~h}^{-1}(p=0.5)$ at Borg 10-11 and outdoors at $6 \mathrm{~km} \mathrm{~h}^{-1}(p=0.05)$ (adjusted for speed in $\left.\mathrm{km} \mathrm{h}^{-1}\right)$. Further, those with motor-complete tetraplegia had significantly lower activity $\mathrm{VO}_{2}$ for setting a table in all absolute values, $p<0.001$ and adjusted for body weight. In addition wheelchair-wheeling outdoors at walking pace showed an increase of 4 times for the motor-complete tetraplegia group and five times for the reference group as compared to watching TV, giving $14 \%$ lower activity $\mathrm{VO}_{2}$ for people with motor-complete tetraplegia than for those in the reference group. The motor-complete tetraplegia people had significantly lower absolute $\mathrm{VO}_{2}$ related to body weight for all exercise activities, $p<0.001$, and their oxygen consumption was almost 50\% lower (Fig. 1). There were small intra-individual variations (SD) in both groups for activity $\mathrm{VO}_{2}$ and AEE in sedentary activities, increasing considerably during exercise activities especially for those with motor-complete paraplegia (Fig. 1).

\section{Discussion}

The main finding in this study was that people with motorcomplete tetraplegia are able to increase their activity $\mathrm{VO}_{2}$ and AEE four times during activities of daily living (NEPA) compared to sedentary activities. Further, exercise activities increase activity $\mathrm{VO}_{2}$ or AEE values almost sevenfold compared to sedentary activities. There were no significant differences regarding REE when $\mathrm{VO}_{2}$ was adjusted for body weight between people with motor-complete tetraplegia and the reference group. The increase in total and activity $\mathrm{VO}_{2}$ adjusted for body weight between desk work and outdoor wheelchair-wheeling was $\sim 25 \%$ lower for people with motor-complete tetraplegia, and was significantly lower for these people in all exercise activities. The present results can be used to estimate energy consumption during activity for people with motor-complete SCI at level C5-C8 within the same range of body weight and BMI for respective gender.

\section{Resting oxygen consumption in motor-complete tetraplegia}

This study is to our knowledge the first to report resting $\mathrm{VO}_{2}$ adjusted for body weight for both genders with motorcomplete tetraplegia. Our result is comparable to that in the Collins et al. study of male participants $(2.54(0.22)$ vs. Collins' $2.52(0.50) \mathrm{ml} \mathrm{O}_{2} \mathrm{~kg}^{-1} \mathrm{~min}^{-1}$ ) [10]. Moreover, one previous study reporting REE in calories during $24 \mathrm{~h}$ (not related to body weight) gave similar results: 1259 (204) kcal per $24 \mathrm{~h}$ vs. our 1195 (206) kcal per $24 \mathrm{~h}$, for male participants with similar BMI [13]. However, using BMI as a descriptor of body composition has its limitations. 


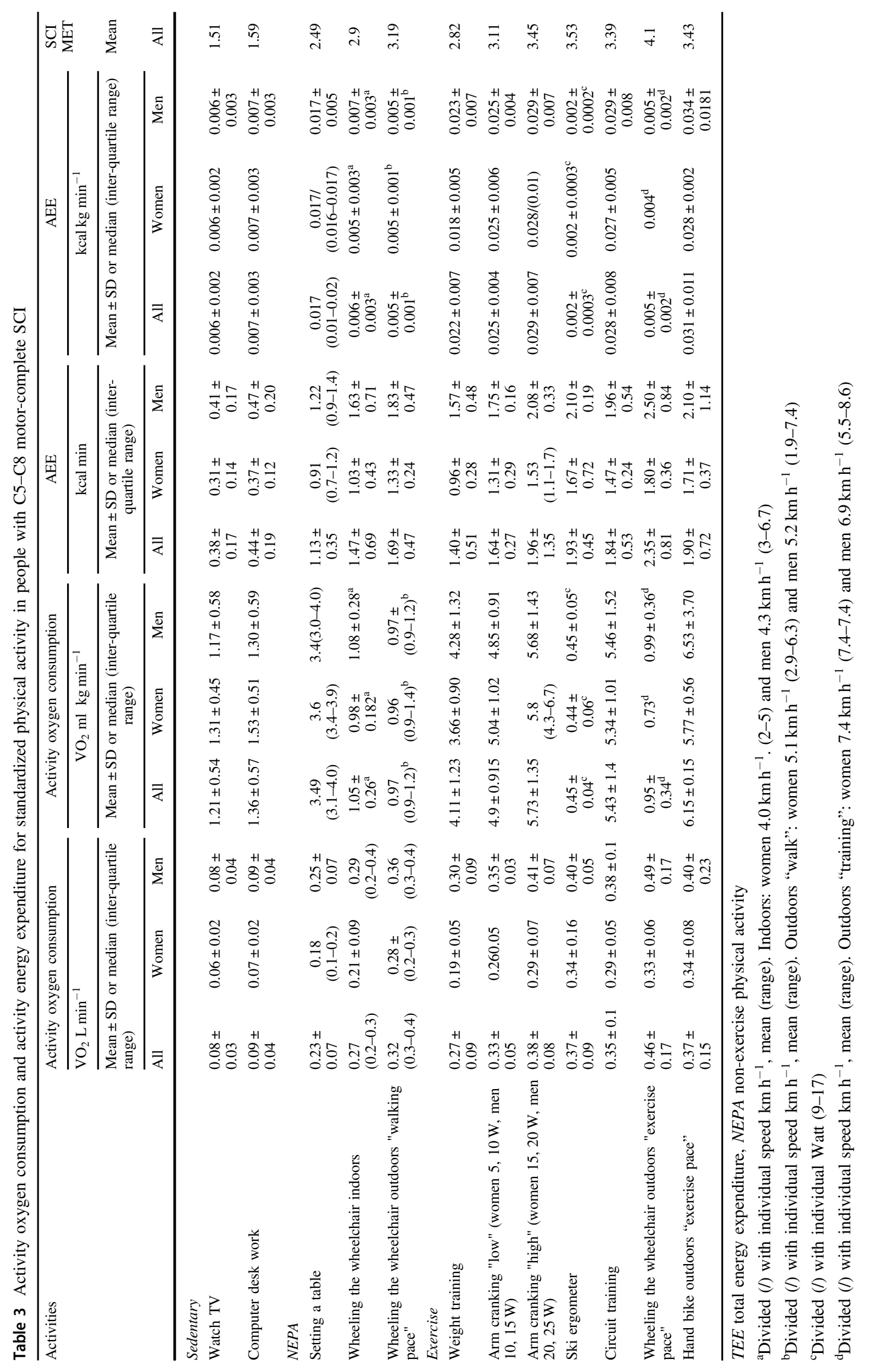


We report no gender differences for resting oxygen consumption when adjusted for body weight. Interestingly, we found small gender differences in REE, and this is of high clinical value for the SCI population. However, the intra-individual variation makes the REE results less generalizable, since REE is such a large proportion of TEE in motor-complete tetraplegia.

\section{Activities in motor-complete tetraplegia}

Previous studies presenting activity $\mathrm{VO}_{2}$ and AEE in people with motor-complete tetraplegia are, to our knowledge, limited. However, total oxygen uptake and TEE have previously been reported by Collins et al., which enables comparisons for some activities [10]. For example, those authors reported similar $\mathrm{VO}_{2}$ values for desk work (3.96 (1.23) $\mathrm{ml} \mathrm{O}_{2} \min ^{-1} \mathrm{~kg}^{-1}$ vs. our 3.85 (0.58) $\mathrm{ml}$ $\mathrm{O}_{2} \mathrm{~min}^{-1} \mathrm{~kg}^{-1}$ ) and for activities of daily living (NEPA) "moving items vs. setting a table", for men in our study. On the other hand values differed for exercise activity, such as weight training and circuit resistance training [10]. The difference in result probably originated from the methodological differences between the two studies. Other differences were sample sizes. Collins' et al. study only included three to four participants, except for deskwork with nine male participants, compared to 19 male and seven female participants in our study. Further, our study is to our knowledge the first to report no gender differences in activities within the motor-complete tetraplegic population for AEE adjusted to body weight, and this is comparable to the result for motor-complete paraplegia [14]. This tallies with previous studies of people with motor-complete paraplegia and is probably explained by the fact that both genders had similar lean body mass adjusted for body weight $[14,24]$. However, these results may not be generalizable to people with a body weight outside the range of this study.

\section{Tetraplegia vs. the reference group with paraplegia}

There were no significant differences in absolute or relative resting $\mathrm{VO}_{2}$ values between the two groups. The REE result is in line with that of Collins et al., which also showed no significant differences in absolute or relative resting $\mathrm{VO}_{2}$ values between the tetraplegia and paraplegia groups [10]. However, other studies report differences in REE ( $\mathrm{kcal} 24 \mathrm{~h}$ ) between these subgroups; nonetheless it is difficult to compare studies especially if the REE is not related to body weight and/or lean body mass [13, 25]. The reported differences between the two subgroups seen in other studies may be explained by the fact that people with motor-complete tetraplegia experience greater loss of lean body mass, i.e. muscle mass, than people with motor-complete paraplegia [26]. Singh et al. reported around $16 \%$ lower lean body mass for people with motor-complete tetraplegia one year post injury. This included a 6\%-lower lean body mass in the trunk and $\sim 10 \%$ lower in the arms for people with tetraplegia compared to those with motor-complete paraplegia [26]. However, skeletal muscle mass alone contributes only about $20 \%$ to REE in the general population [27]. This concurrence can also be demonstrated in this study by comparing the $\mathrm{VO}_{2}\left(\mathrm{~L} \mathrm{~min}^{-1}\right)$, which was $13 \%$ higher for the reference group than for the people with motor-complete tetraplegia $(0.18(0.51) \mathrm{L}$ vs. $0.16(0.26) \mathrm{L})$. Moreover, the intra-individual difference (expressed as SD) in relative $\mathrm{VO}_{2}$ for tetraplegia $(0.26)$ was only half of the difference compared to what we reported for motor-complete paraplegia (0.51). This may be explained by a more homogenous sample with smaller differences in weight and consequently in BMI. This makes the generalizability for REE low for both groups, indicating that REE should be measured instead of estimating. Further, there were no significant differences between the two subsamples for sedentary activities, which indicate that sedentary activities are closely related to REE.

The importance of NEPA for increasing daily EE has been highlighted in the general population [28, 29]. For persons with an SCI, normal essential day-to-day tasks have been suggested to play an important role in TEE [30]. Further, therapeutic lifestyle interventions that include accumulating activity in small bouts during a day, have shown positive effects, such as decreased adiposity similar to that in structured exercise programs in the general population [31]. Consequently, the increase in AEE through wheelchair- wheeling indoors/outdoors and setting a table compared to a sedentary activity is important for both conditions. For example, a person with motorcomplete tetraplegia/paraplegia with a bodyweight of $66 \mathrm{~kg}$ wheeling a wheelchair indoors at $4 \mathrm{~km} \mathrm{~h}^{-1}$ for $60 \mathrm{~min}$ in bursts expends $95 \mathrm{kcal}$ extra above REE [14]. Additionally, if the same person does household activities (e.g. setting a table or moving items) for $60 \mathrm{~min}$, AEE are $67 \mathrm{kcal}$ (tetraplegia) and $87 \mathrm{kcal}$ (paraplegia). NEPA has also been associated with improved health and reduction in risk factors in the general population, with similar results in paraplegia [28, 29, 32, 33]. Inactive people with tetraplegia have significantly greater insulin resistance than their active counterparts [33]. Moreover, Hetz et al. [34] reported that both people with paraplegia and those with tetraplegia had significantly lower low-density lipids and cholesterol through spending more time wheeling their wheelchair and moving about during daily living. The current adapted guidelines for PA focus mainly on aerobic and strength training [6]. The present result implies that NEPA is suitable for persons with motor-complete tetraplegia, 


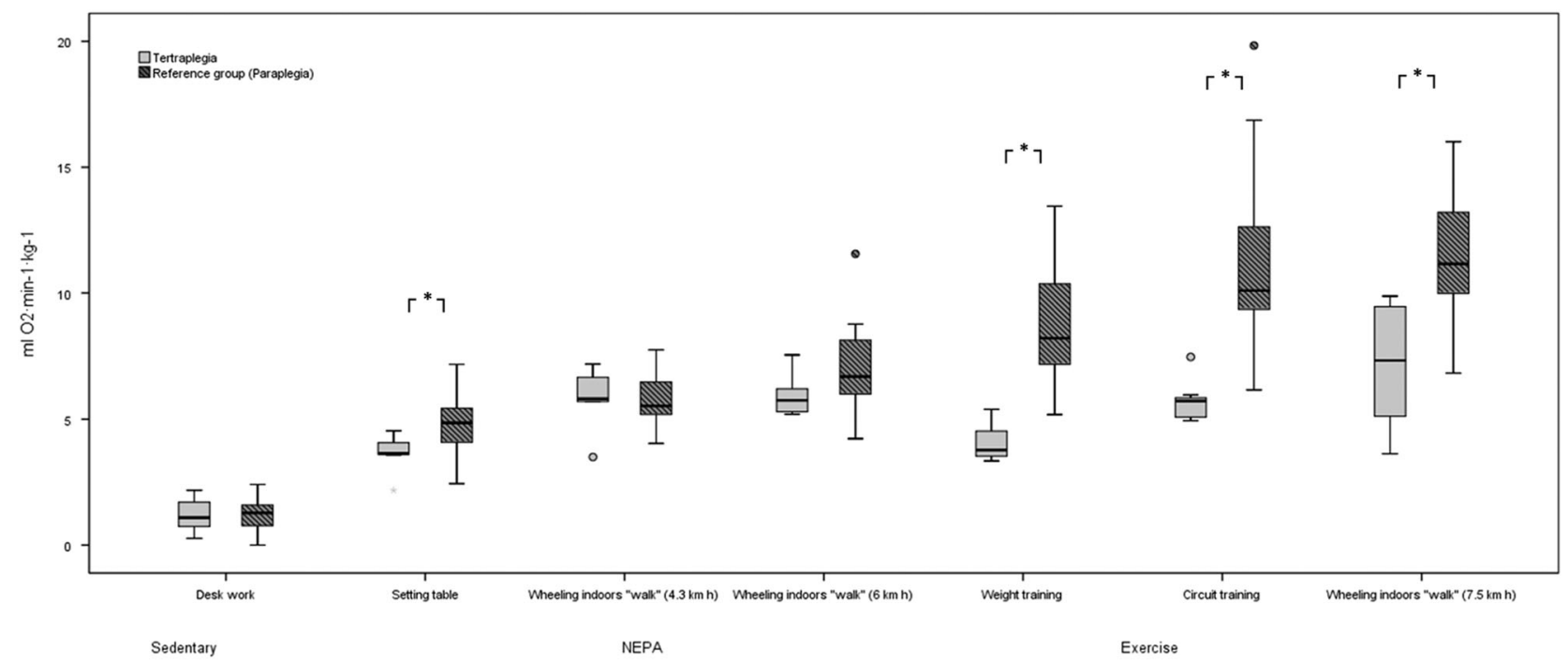

Fig. 1 Descriptive and comparative statistics of activity oxygen consumption related to bodyweight between motor-complete tetraplegia and motor-complete paraplegia. $\ulcorner *\rceil=$ Significant difference

$p<0.01$ (Mann-Whitney $U t$-test). Wheeling wheelchair was calculated from individual activity $\mathrm{VO}_{2} \mathrm{ml} \mathrm{O}_{2} \mathrm{~kg}^{-1} \mathrm{~min}^{-1}$ multiplied with mean speed of both groups. ${ }^{\circ}=$ outliers

since these activities increase AEE almost fourfold compared to sedentary activities. Moreover, they are low-to-moderate and below the lactic threshold. Therefore, highlighting and quantifying NEPA as a supplement to existing PA recommendations could be of clinical importance.

The only significant difference between the groups in NEPA was setting a table, which could be because there were no measurements for speed of movement and the limited hand function associated with motor-complete tetraplegia.

Exercise activities showed an increase in AEE up to 6 times for the people with motor-complete tetraplegia and 14 times for the reference group. For example, $45 \mathrm{~min}$ of circuit resistance training for a person with a motor-complete tetraplegia, bodyweight $66 \mathrm{~kg}$, consumes $83 \mathrm{kcal}$ compared to $166 \mathrm{kcal}$ for a person with motor-complete paraplegia, giving half the AEE $\mathrm{kcal} \mathrm{kg}^{-1}$ for motor-complete tetraplegia. All exercise activities significantly differed between the two samples, which may be explained by the greater proportion of reduced muscle mass and the impairment in the ANS among those with motor-complete tetraplegia. This predisposes these people to a limited cardiovascular response, where the difference is a result of the insufficient response from the ANS together with less muscle mass [19, $35,36]$. However, some people with motor-complete tetraplegia seem to retain this function i.e. they have autonomic control [37]. Still, people with motor-complete tetraplegia may improve their physical fitness from exercise activities, such as circuit resistance, thus gaining EE, muscle strength, cardiorespiratory capacity $\left(\mathrm{VO}_{2 \text {-peak }}\right)$ and fatigue resistance [38-40]. These improvements are of importance for a person's independence and for shoulder protection and injury prevention [41].

\section{Strengths and limitations}

The strengths of this study include the data collection which was carried out 'close to real life'. The same methods and procedures were used during the data collection as for the reference group with motor-complete paraplegia, which made it feasible to further deepen the analysis between the two subsamples. To our knowledge, no other studies include more subjects than ours within the same homogenous SCI subgroup. The inclusion of AEE data, and not just TEE, is of great clinical value as it reflects the actual energy demand of the activity performed. Moreover, the result for the reference group with tetraplegia showed a rather small intra-individual difference for activity $\mathrm{VO}_{2}$ per $\mathrm{kg}$ of bodyweight compared to those with motorcomplete paraplegia. This is probably because our participants needed low body weight to be able to perform activities requiring them to carry their own weight in the wheelchair.

Although the inclusion of females with tetraplegia is a strength, the number of female participants reflects the proportion in the SCI population and was therefore rather low. Further, the study measured only the participants' weight and height, with subsequent calculation of BMI, and the latter has its limitations concerning description of body composition [42]. This limits our understanding of the intra-individual and the gender differences between tetraplegia and paraplegia. Other measurements that reflect body composition may have been preferable, such as DEXA. The 
present results are not generalizable for the whole SCI population, but only for persons with motor-complete tetraplegia who are able to wheel a wheelchair unaided within the range of bodyweight and BMI.

\section{Conclusion}

Persons with motor-complete tetraplegia can increase EE up to three-to-four times when engaging in non-exercise physical activity compared to sedentary activities. Significant differences between the motor-complete tetraplegia group and the paraplegia reference group were seen especially in EE via exercise activities. The finding of the potentially significant contribution of non-exercise physical activity in daily life to increase total daily EE is of particular clinical relevance. These activities are suitable for longer periods, as non-exercise activities are performed mainly at low-tomoderate intensity levels below the lactate threshold, and spare the shoulders. This might help motivate the individual, and be of clinical importance when designing lifestyle intervention programs.

Acknowledgements This study was supported by the Promobilia Foundation, the Märta, and Gunnar V Philipson Foundation, the Norrbacka-Eugenia Foundation, the Swedish Association for Survivors of Accident and Injury (RTP), the Spinalis Foundation and NEURO Sweden. We thank all the participants and Mikael Flockheart for all help with the data collection. Finally, we would like to thank Professor Mark S Nash of the Miami Project for inspiring us to complete this work.

\section{Compliance with ethical standards}

Conflict of interest The authors declare that they have no competing interests.

\section{References}

1. Wahman K, Nash MS, Lewis JE, Seiger A, Levi R. Cardiovascular disease risk and the need for prevention after paraplegia determined by conventional multifactorial risk models: the Stockholm spinal cord injury study. J Rehabil Med. 2011;43:237-42.

2. Weaver FM, Collins EG, Kurichi J, Miskevics S, Smith B, Rajan $\mathrm{S}$, et al. Prevalence of obesity and high blood pressure in veterans with spinal cord injuries and disorders: a retrospective review. Am J Phys Med Rehabil. 2007;86:22-9.

3. Myers JL, Kiratli M, Lee M. Cardiovascular disease in spinal cord injury: an overview of prevalence, risk, evaluation, and management. Am J Phys Med Rehabil. 2007;86:142-52.

4. Fisher JA, McNelis MA, Gorgey AS, Dolbow DR, Goetz LL. Does upper extremity training influence body composition after spinal cord injury? Aging Dis. 2015;6:271-81.

5. Kressler J, Cowan RE, Bigford GE, Nash MS. Reducing cardiometabolic disease in spinal cord injury. Phys Med Rehabil Clin N Am. 2014;25:573.
6. Physical activity guidelines for Adults with Spinal Cord Injury. http://sciactioncanada.ca/docs/guidelines/Physical-ActivityGuidelines-for-Adults-with-a-Spinal-Cord-Injury-English.pdf Accessed on 29 April 2016.

7. Bauman WA, La Fountaine MF, Cirnigliaro CM, Kirshblum SC, Spungen AM. Lean tissue mass and energy expenditure are retained in hypogonadal men with spinal cord injury after discontinuation of testosterone replacement therapy. J Spinal Cord Med. 2015;38:38-47.

8. Buchholz AC, McGillivray CF, Pencharz PB. Differences in resting metabolic rate between paraplegic and able-bodied subjects are explained by differences in body composition. Am J Clin Nutr. 2003;77:371-78.

9. Abel T, Platen P, Vega SR, Schneider S, Struder HK. Energy expenditure in ball games for wheelchair users. Spinal Cord. 2008;46:785-90.

10. Collins EG, Gater D, Kiratli J, Butler J, Hanson K, Langbein WE. Energy cost of physical activities in persons with spinal cord injury. Med Sci Sports Exerc. 2010;42:691-700.

11. Yilmaz B, Yasar E, Goktepe S, Alaca R, Yazicioglu K, Dal U, et al. Basal metabolic rate and autonomic nervous system dysfunction in men with spinal cord injury. Obesity. 2007;15:2683-87.

12. Cox SAR, Weiss SM, Posuniak EA, Worthington P, Prioleau M, Heffley G. Energy-expenditure after spinal-cord injury-an evaluation of stable rehabilitating patients. J Trauma. 1985;25:419-23.

13. Gorgey AS, Gater DR. Regional and relative adiposity patterns in relation to carbohydrate and lipid metabolism in men with spinal cord injury. Appl Physiol Nutr Metab 2011;36:107-14.

14. Holmlund T, Ekblom-Bak E, Franzen E, Hultling C, Wikmar LN, Wahman K. Energy expenditure in people with motor-complete paraplegia. Spinal Cord. 2017;55:774-81.

15. Nevin AN, Steenson J, Vivanti A, Hickman IJ. Investigation of measured and predicted resting energy needs in adults after spinal cord injury: a systematic review. Spinal Cord. 2015;54:248-53.

16. Moore CD, Craven BC, Thabane L, Laing AC, Frank-Wilson AW, Kontulainen SA, et al. Lower-extremity muscle atrophy and fat infiltration after chronic spinal cord injury. J Musculoskelet Neuronal Interact. 2015;15:32-41.

17. Gorgey AS, Dolbow DR, Dolbow JD, Khalil RK, Castillo C, Gater DR. Effects of spinal cord injury on body composition and metabolic profile-Part I. J Spinal Cord Med. 2014;37:693-702.

18. Currie KD, West CR, Hubli M, Gee CM, Krassioukov AV. Peak heart rates and sympathetic function in tetraplegic nonathletes and athletes. Med Sci Sports Exerc. 2015;47:1259-64.

19. Garstang SV, Miller-Smith SA. Autonomic nervous system dysfunction after spinal cord injury. Phys Med Rehabil Clin N Am. 2007;18:275-96.

20. Penn RD. Intrathecal baclofen for severe spasticity. Ann N Y Acad Sci. 1988;153:157-66.

21. Borg BG. Borg-RPE-skalan. En enkel metod för bestämning av upplevd ansträngning. Stockholm: Borg Perception; 1994.

22. Borg GA. Psychophysical bases of perceived exertion. Med Sci Sports Exerc. 1982;14:377-81.

23. Jacobs PL, Nash MS, Rusinowski JW. Circuit training provides cardiorespiratory and strength benefits in persons with paraplegia. Med Sci Sports Exerc. 2001;33:711-7.

24. Lee MZ, Hedrick W, Fernhall B, Zhu W. Determining metabolic equivalent values of physical activities for persons with paraplegia. Disabil Rehabil. 2010;32:336-43.

25. Yilmaz B, Yasar E, Goktepe AS, Onder ME, Alaca R, Yazicioglu $\mathrm{K}$, et al. The relationship between basal metabolic rate and femur 
bone mineral density in men with traumatic spinal cord injury. Arch Phys Med Rehabil. 2007;88:758-61.

26. Singh R, Rohilla RK, Saini G, Kaur K. Longitudinal study of body composition in spinal cord injury patients. Indian J Orthop. 2014;48:168-77.

27. Gallagher D, Belmonte D, Deurenberg P, Wang Z, Krasnow N, Pi-Sunyer FX, et al. Organ-tissue mass measurement allows modeling of REE and metabolically active tissue mass. Am J Physiol Endocrinol Metab. 1998;275:249-58.

28. Levine JA. Nonexercise activity thermogenesis-liberating the life-force. J Intern Med. 2007;262:273-87.

29. Hamilton MT, Hamilton DG, Zderic TW. Role of low energy expenditure and sitting in obesity, metabolic syndrome, type 2 diabetes, and cardiovascular disease. Diabetes. 2007;56:2655-67.

30. Tremblay MS, Esliger DW, Tremblay A, Colley R. Incidental movement, lifestyle-embedded activity and sleep: new frontiers in physical activity assessment. Can J Public Health. 2007;98(Suppl 2):208-17

31. Dunn AL, Marcus BH, Kampert JB, Garcia ME, Kohl HW III, Blair SN. Comparison of lifestyle and structured interventions to increase physical activity and cardiorespiratory fitness: a randomized trial. JAMA. 1999;281:327-34.

32. Hamasaki H, Yanai H, Mishima S, Mineyama T, YamamotoHonda R, Kakei M, et al. Correlations of non-exercise activity thermogenesis to metabolic parameters in Japanese patients with type 2 diabetes. Diabetol Metab Syndr. 2013;5:26.

33. Buchholz AC, Martin Ginis KA, Bray SR, Craven BC, Hicks AL, Hayes $\mathrm{KC}$, et al. Greater daily leisure time physical activity is associated with lower chronic disease risk in adults with spinal cord injury. Appl Physiol Nutr Metab. 2009;34:640-7.
34. Hetz SP, Latimer AE, Buchholz AC, Martin Ginis KA. Increased participation in activities of daily living is associated with lower cholesterol levels in people with spinal cord injury. Am J Phys Med Rehabil. 2009;90:1755-9.

35. Gondim FA, Lopes AC Jr., Oliveira GR, Rodrigues CL, Leal PR, Santos AA, et al. Cardiovascular control after spinal cord injury. Curr Vasc Pharmacol. 2004;2:71-9.

36. Krassioukov A, Claydon VE. The clinical problems in cardiovascular control following spinal cord injury: an overview. Prog Brain Res. 2006;152:223-29.

37. Mills PB, Krassioukov A. Autonomic function as a missing piece of the classification of paralympic athletes with spinal cord injury. Spinal Cord. 2011;49:768-76.

38. Kressler J, Burns PA, Betancourt L, Nash MS. Circuit training and protein supplementation in persons with chronic tetraplegia. Med Sci Sports Exerc. 2014;46:1277-84.

39. DiCarlo SE. Effect of arm ergometry training on wheelchair propulsion endurance of individuals with quadriplegia. Phys Ther. 1988;68:40-4.

40. DiCarlo SE. Improved cardiopulmonary status after a two-month program of graded arm exercise in a patient with C6 quadriplegia. A case report. Phys Ther. 1982;62:456-9.

41. Devillard X, Rimaud D, Roche F, Calmels P. Effects of training programs for spinal cord injury. Ann Readapt Med Phys. 2007;50:490-8. 80-9

42. Jones LM, Goulding A, Gerrard DF. DEXA: a practical and accurate tool to demonstrate total and regional bone loss, lean tissue loss and fat mass gain in paraplegia. Spinal Cord. 1998;36:637-40. 